\title{
Fatigue life of E-glass fibre/zirconia/epoxy hybrid composites
}

\author{
V K SRIVASTAVA \\ Department of Mechanical Engineering, Institute of Technology, Banaras Hindu \\ University, Varanasi 221005 , India \\ MS received 12 December 1987; revised 29 February 1988
}

\begin{abstract}
An ultrasonic technique has been used to evaluate the degradated fatigue life of glass fibre/zirconia hybrid composites in different concentrations of sodium chloride and sulphuric acid. Results indicate that reduction in fatigue life of hybrid composites increases with increase in ultrasonic attenuation. Ultrasonic attenuation can be used to predict the fatigue life of hybrid composites before and after service.
\end{abstract}

Keywords. Fatigue; hybrid composite materials; ultrasonic attenuation; acidic environments.

\section{Introduction}

Fibre reinforced plastic (FRP) composites are extensively used in the chemical process industry for applications such as pipe-work, reaction vessels and storage tanks. The conditions are often severe, frequently combining pressure, high temperatures and chemically reactive reagents. In most environments glass fibre reinforced plastic (GRP) composite is reasonably inert, especially when the component is not subjected to service loads (Hogg et al 1981). Rege and Lakkad (1983) studied the effect of soaking in salt water and distilled water at various temperatures on the mechanical properties of GRP and carbon FRP composites. They found that the degradation in compressive interlaminar and flexural strength is much more severe in salt water than in distilled water. Niesse (1982) reported that when the $\mathrm{E}$ and $\mathrm{C}$-glass fibres are exposed to $35 \% \mathrm{HCl}$ at ambient temperature in laboratory, several changes such as colour or loss of glass may occur in FRP laminates which have little apparent effect on performance. Tensile strength of GRP composites is reduced when the diffusing molecules of chemicals rupture the intermolecular bond in the epoxy resin at the interface (Regester 1969). Davis et al (1982) who studied the corrosion fatigue and stress corrosion characteristic of metal matrix composites in sea water reported that the fatigue strength of $\mathrm{SiO}_{2}$ coated fibre composites is significantly reduced at lives $>5 \times 10^{6}$ cycles due to degradation of the composite by corrosion. Recent advances in manufacturing technology of fibre reinforced sheet moulding compound (SMC) have made the short fibre composite an attractive candidate for load-bearing structural applications due to its advantages in processability, high volume production, part consolidation, low tooling costs, favourable mechanical properties and increased structural applications. Automotive structural components experience repeated loading during service (Riegner and Hsu 1982). The homogeneous fatigue damage decreases rapidly with the loading cycle due to the combined effects of rapid depletion of micro-crack initiation sites and the presence of various crack-arrest mechanisms (Wang and Chim 1983). Evaluation of strength loss after use is particularly important in composite materials since moisture uptake and fatigue can cause a drop in strength. Non-destructive evaluation methods are needed to find not only individually isolated defects but also those which are 
subtle and distributed throughout the material. Srivastava and Prakash (1987) studied the reduction in ultimate performance of GRP composite by the acoustoultrasonic technique. Ultrasonics (Joshi and Green 1972; Williams and Doll 1980; Srivastava and Prakash 1987) have also been used to determine the fatigue damage and fatigue life as well as the percentage of voids in composite materials (Stone and Clarke 1975). The present work is concerned primarily with the effect of $\mathrm{H}_{2} \mathrm{SO}_{4}$ and $\mathrm{NaCl}$ on glass fibre/zirconia hybrid composites. The degradated fatigue life of hybrid composites is evaluated by the ultrasonic method.

\section{Experimental procedure}

The unidirectional glass fibre/zirconia hybrid composites were prepared by E-glass fibre, epoxy resin (CY-205 araldite and HY-951 hardener) and zirconia powder by hand technique. The diameter and length of fatigue specimens were 15 and $120 \mathrm{~mm}$ respectively. The fibre volume fraction of the E-glass fibres was $49 \cdot 7 \%$. These fatigue specimens were immersed in sulphuric acid solution $\left(40 \% \mathrm{H}_{2} \mathrm{SO}_{4}\right.$ and $\left.60 \% \mathrm{H}_{2} \mathrm{SO}_{4}\right)$ and sodium chloride $(40 \% \mathrm{NaCl}$ and $60 \% \mathrm{NaCl})$. Every four days, three specimens were removed from each of the chemical solutions. These specimens were then used for ultrasonic and fatigue testing. The values of ultrasonic attenuation were recorded by the ultrasonic method (UFD-67B) for each specimen before and after immersing in chemical solutions. Seven values of ultrasonic attenuation were determined for each specimen, the coefficient of variation between the reading being $0 \cdot 85$. The average ultrasonic attenuation value was taken to determine the degradated fatigue life and energy required for fracture per unit volume of hybrid composites and ultrasonic attenuation. The values of fatigue life and energy required for fracture per unit volume of hybrid composites were obtained (i.e. specimens with known ultrasonic attenuation) by using the Amsler universal hammer machine. Also, the average values of fatigue life (three specimens) were taken for the above study, the coefficient of variation between the reading being 0.685 . The percentage values in ultrasonic attenuation in different concentrations of chemical solution such as $40 \%$ $\mathrm{NaCl}, 60 \% \mathrm{NaCl}, 40 \% \mathrm{H}_{2} \mathrm{SO}_{4}$ and $60 \% \mathrm{H}_{2} \mathrm{SO}_{4}$ showed an increase from the initial and degradated values of hybrid composites. The values of reduction in fatigue life and reduction in energy required for fracture per unit volume of those specimens having known value of ultrasonic attenuation were also obtained from the initial and degradated values of hybrid composites.

\section{Results and discussion}

The relation between the immersion time and percentage increase in ultrasonic attenuation is shown in figure 1 . The results indicate that ultrasonic attenuation increases with increase in the immersion time of hybrid composite in different concentrations of chemical solutions. This increase in ultrasonic attenuation therefore indicates increase in the percentage of voids (Stone and Clarke 1975). This is because the surface hardness, modulus and strength of the epoxy resin are always reduced due to chemical attacks. This may be due to the effect of acid on the intermolecular bond in the epoxy resin and also due to the effect of acid on the interfaces between fibres and resin. The corrosive effect of sulphuric acid is more 


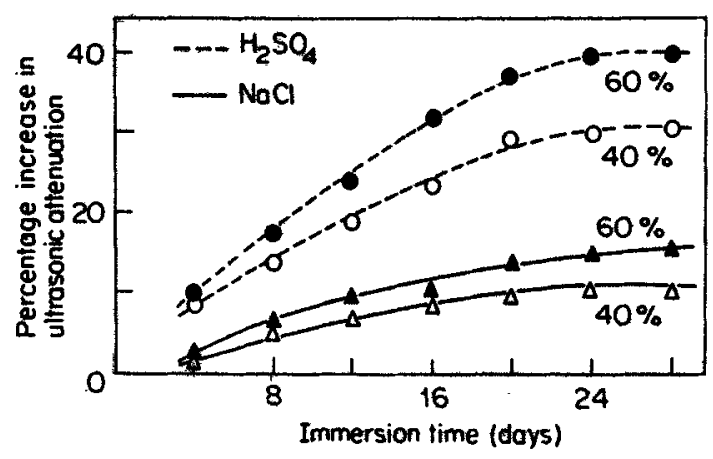

Figure 1. Percentage increase in ultrasonic attenuation vs immersion time for glass fibre $i$ zirconia hybrid composite.

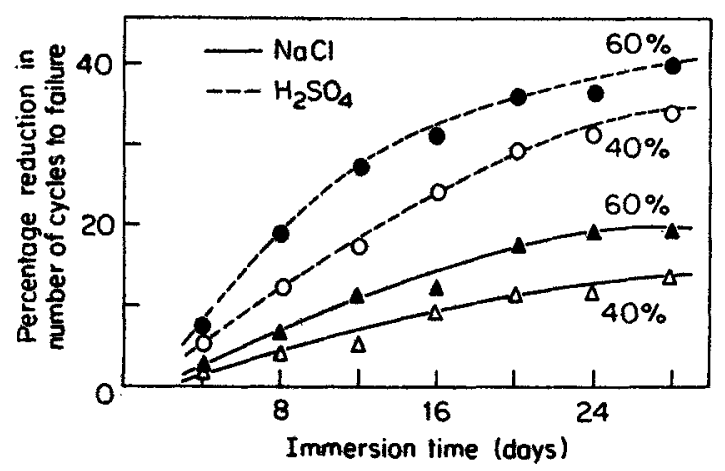

Figure 2. Percentage reduction in number of cycles to failure vs immersion time for glass fibre/zirconia hybrid composite.

pronounced compared to sodium chloride. The hybrid composite specimens also absorb water from the diluted acids, which is due to capillary action along the fibres (an effect known as wicking). The effect of chemicals on hybrid specimens tends to saturate after 20 days. Figure 2 shows that the percentage reduction in fatigue life (number of cycles to failure) increases with increase in the immersion time of hybrid composites in different concentrations of chemical solutions, confirming that the quality of hybrid specimen decreases in acidic environments. From figure 3 it is also clear that the percentage reduction in energy required for fracture per unit volume increases with increasing immersion. Since the fibre, zirconia filler and resin bonds are broken by chemical solutions, the results also show that the higher percentage of chemicals are broken more than the low percentage of chemicals. Ishai (1975) showed that the nature of the epoxy resin is an important factor in determining the extent of hydrothermal damage. The fatigue properties are also saturated after 20 days immersion of hybrid composites in different chemical solutions. From these results, it is reasonable to conclude that the percentage reduction in fatigue life and percentage reduction in energy required for fracture per unit volume increases with increase in the percentage and change in ultrasonic attenuation as shown in figures 4 and 5 confirming that ultrasonic attenuation is a sensitive indicator of defects in zomposites (Stone and Clarke 1975). The lower values of ultrasonic attenuation 


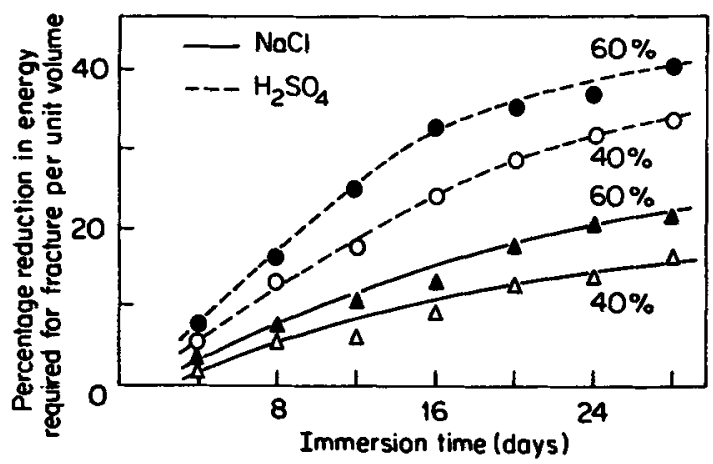

Figure 3. Percentage reduction in energy required for fracture per unit volume vs immersion time for glass fibre/zirconia hybrid composite.

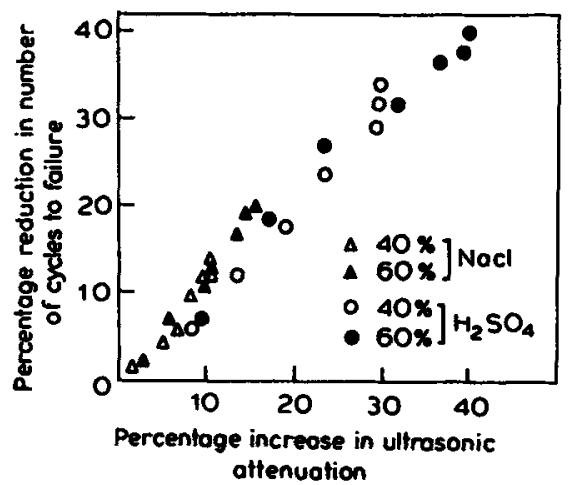

Figure 4. Percentage reduction in number of cycles to failure vs percentage increase in ultrasonic attenuation for glass fibre/zirconia hybrid composite.

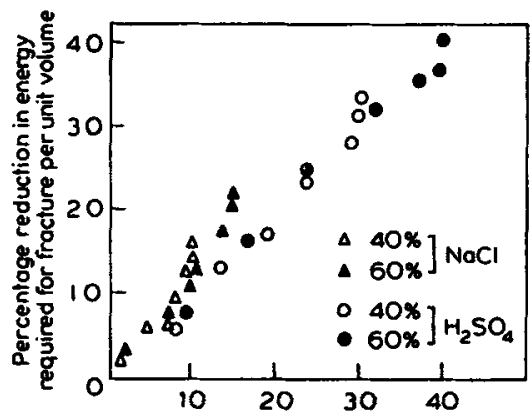

Percentage increose in ultrasonic attenuation

Figure 5. Percentage reduction in energy required for fracture per unit volume vs percentage increase in ultrasonic attenuation for glass fibre/zirconia hybrid composite.

indicate that the quality of hybrid composite materials is better than the higher values of ultrasonic attenuation. There is a considerable scatter in the results, particularly at the higher immersion time, but reasonable approximations of the fatigue rate can be obtained. 
The present results show that the ultrasonic technique can be used for evaluating the degradated fatigue life of hybrid composites in acidic environments.

\section{References}

Davis D A, Vassilaros M G and Gudas J P 1982 Mater. Perform. 2138

Hogg P J, Hull D and Legg M 1981 Proc. Int. Conf. on Composite Structures (Scotland: Paisley College of Tech.)

Ishai O 1975 Polym. Eng. Sci. 15486

Joshi N R and Green Jr R E 1972 Eng. Fract. Mech. 4577

Niesse J E 1982 Mater. Perform. 2125

Rege S K and Lakkad S C 1983 Fibre Sci. Technol. 19317

Regester R F 1969 Corrosion 25157

Riegner D A and Hsu J C 1982 Proceedings of the SAE Fatigue Conference 11 237-247.

Srivastava V K and Prakash R 1987 Int. J. Fatigue 9109

Srivastava V K and Prakash R 1987 Proc. VI Int. Conf. on Composite Materials and Second European Conf. on Composite Materials

Stone D E W and Clarke B 1975 NDT Int. 8137

Wang S S and Chim E S M 1983 J. Compos. Mater. 17114

Williams Jr J H and Doll B 1980 J. Mater. Eval. 3833 